\title{
Trauma: phenomenological causality and implication
}

\author{
Lillian Wilde ${ }^{1}$ \\ Accepted: 15 December 2020 /Published online: 13 January 2021 \\ (C) The Author(s) 2021
}

\begin{abstract}
The relationship between traumatic experiences and subsequent distress is not well understood, and little research focuses on the lived experience of psychological trauma. I draw on Louis Sass's phenomenological taxonomy to address this lacuna. I present his differentiation between relations of phenomenological causality and implication and demonstrate that his taxonomy can be applied to experiences of trauma. Relations of phenomenological causality and implication can be identified in the genesis and constitution of post-traumatic distress. My adaptation of Sass's taxonomy will furthermore offer an extension and development of his account, applying it to the study of post-traumatic experiences and elaborating it in the process. I shall demonstrate that whether experiences occur synchronically or diachronically is not essential to their categorization in terms of phenomenological implication and causality, respectively. I will show that an alteration in perception or behavior post trauma might temporally succeed the traumatizing event while, at the same time, being implied in the experience of the event. Thereby, I demonstrate how phenomenology may contribute to a detailed understanding of experiences of trauma. Scrutiny of traumatic experiences furthermore promises to contribute to the philosophical discourse on causality, implication, and temporal experience.
\end{abstract}

Keywords Post-traumatic experience $\cdot$ Temporality $\cdot$ Trust $\cdot$ PTSD $\cdot$ Causality $\cdot$ Implication

\section{Introduction}

"Traumatic experiences do leave traces," Bessel van der Kolk writes in his bestseller on trauma (van der Kolk 2015), and this is hardly disputable. Trauma presents us with severely disruptive experiences that have often long-lasting effects on the affected individual. Mental health issues such as those commonly associated with PostTraumatic Stress Disorder (PTSD), Major Depression, Anxiety, or Depersonalization/

Lillian Wilde

lillian.wilde@york.ac.uk

1 Department of Philosophy, University of York, York, Heslington YO10 5DD, UK 
Derealization Disorder are all known to follow devastating experiences (APA 2013). A wealth of literature offers varying suggestions as to what exactly causes these kinds of post-traumatic suffering. Much of the consensus boils down to alterations in brain functioning (cf., e.g.: "We now know that their behaviors [...] are caused by actual changes in the brain" van der Kolk 2015). Little research, however, focuses explicitly on the details of how a potentially traumatizing event is experienced and how this experience relates to the development of subsequent distress. The diachronic relationship between a potentially traumatizing event and adverse mental health outcomes is either described vaguely, e.g. as "psychological distress following exposure to a traumatic or stressful event" (APA 2013, p. 265, my emphasis), being "associated" with the event (NICE 2018), or it is conceptualized in exclusively causal terms, as the above van der Kolk quotation exemplifies. I suggest that a detailed phenomenological description of the experiences of trauma and their various relations may refine our understanding of post-traumatic distress, helping thus to shape prevention and treatment.

I suggest a twofold approach, scrutinizing 1) phenomenological causality and 2) phenomenological implication in the genesis and constitution of post-traumatic distress. I draw here on Louis Sass's phenomenological taxonomy, which focuses specifically on schizophrenia (Sass and Parnas 2007; Sass 2014; Sass 2010). It includes six ways in which the experiences of schizophrenia and their relation to one another can be conceptualized. Phenomenological implication encompasses three relations that are identified as synchronic, describing symptoms that occur simultaneously: equiprimordial, constitutive, and expressive relations. Phenomenological causality encompasses three relations that are identified as diachronic, accounting for those experiences occurring in succession: primary, consequential, and compensatory relations. While Sass focuses his research on the symptoms typical of schizophreniaspectrum disorders, he intended his phenomenological taxonomy to be generally applicable. ${ }^{1}$

In the following, I shall demonstrate how it might be applied to experiences of trauma. In the context of trauma, three main relationships can be identified: I. the relationship between the traumatizing event and the individual's experience thereof (at the time of its occurrence or later); II. the relationship between the individual's experience at the time of the event and subsequent, post-traumatic experiences of distress; and III. the relationship between the various alterations in post-traumatic experience, such as those commonly conceptualized as symptoms of PTSD. ${ }^{2}$ I will focus here on the second relationship and demonstrate how it can be conceptualized in more than causal terms, thus applying Sass's taxonomy to experiences of trauma. ${ }^{3} \mathrm{My}$ adaptation will furthermore offer an extension and development of his account, applying it to the study of post-traumatic experiences and elaborating it in the process. I shall demonstrate that whether experiences occur synchronically or diachronically is not essential to their categorization in terms of phenomenological implication and causality, respectively. I will show that an alteration in perception or behavior post trauma might

\footnotetext{
${ }^{1}$ Sass (personal communication)

2 The question of what justifies the diagnosis with a mental disorder is one I shall not address in this paper.

${ }^{3}$ The third relationship between the various post-traumatic experiences can follow along similar lines as the first, as it is a relationship between experiences, too.
} 
temporally succeed the traumatizing event while, at the same time, being implied in the experience of the event. Sass and Parnas are open to the possibility of diachronic implication, as they acknowledge in an endnote (Sass and Parnas 2007, pp. 76, endnote 16). However, they do not explore either phenomenon in any detail. The final section of this paper thus serves as an expansion of their account by describing diachronic relations of implication in experiences of trauma. I will begin with an elaboration on phenomenological causality: first in Sass's terms, then applied to relations of trauma. Thereafter, I shall proceed along similar lines in my scrutiny of phenomenological implication, before parting ways with Sass's taxonomy in order to explore diachronic implication in experiences of trauma.

\section{Phenomenological causality}

Phenomenology has a long tradition of being applied to the study of psychopathologies, most notably schizophrenia and depression (e.g. Fuchs 2013; Fuchs and Röhricht 2017; Jaspers 1963; Parnas and Gram Henriksen 2016; Ratcliffe 2018; Sass et al. 2017). In these areas, it has proven to be a valuable tool for scrutinizing the individual's experience of themselves, the world, and others. With very few exceptions (Ataria 2018; Ratcliffe 2017; Ratcliffe et al. 2014), it has not yet been applied to the study of trauma. I shall demonstrate in the following that it can offer valuable insights in regard to the way traumatic events and subsequent alterations in perception and behavior are experienced. Traditionally, phenomenology is deemed to be a largely descriptive method. However, Sass (Sass 2014; Sass 2010; Sass and Parnas 2007) argues for the explanatory value of the phenomenological method: a view that finds resonance with other contemporary phenomenological authors (e.g. Nordgaard and Henriksen 2018; Schmidt 2018). The detailed description of experience, pathological or not, and the differentiation of causal and other relations - which I shall come to discuss shortlycan add to the explanation of these experiences (Ratcliffe 2020). Sass focuses his research first and foremost on schizophrenia and the ipseity or self-disturbance involved. His main focus lies on three disturbances present in but not limited to schizophrenia-spectrum disorders: hyperreflexivity, diminished self-presence and disturbed grip or hold on the world. ${ }^{4}$ These alterations of the experience of oneself in the world are not independent from one another but are closely interrelated, as his taxonomy demonstrates.

\subsection{Louis Sass's phenomenological taxonomy of causal relations}

The question of causality is not restricted to post-traumatic experiences and is widely debated in psychopathological literature. While the traditional disease model assumes

\footnotetext{
4 'Hyperreflexivity' is a heightened, exaggerated awareness of oneself and one's experience. 'Diminished selfpresence'-also 'diminished self-affection' in earlier publications - describes the sense of alienation from oneself and one's experience. 'Disturbed grip on the world' refers to the way in which objects appear somehow strangely off (Sass and Parnas 2007, p. 68 f.). These disturbances are central to schizophrenia and thus serve as prime examples for Sass's taxonomy. For a discussion of the relationship between the symptoms of schizophrenia and the disturbances experienced after trauma, see e.g. Bendall et al. 2008; Read et al. 2001; Sass et al. 2013.
} 
that symptoms of psychopathologies are caused by an underlying disease entity (in parallel with physical ailments, e.g. the headache and dizziness caused by a brain tumor) (McNally et al. 2015), a newer network approach argues for psychological disorders being "systems of causally connected symptoms" (Borsboom and Cramer 2013, p. 93). A detailed discussion of the various kinds of relations that hold between symptoms and their causes, if any can be identified, is lacking in both models. Louis Sass's phenomenological taxonomy offers just that. On his account, causality describes relations between symptoms and their cause that are identified as diachronic, accounting for those symptoms that occur in succession and do not merely correlate. He identifies three such causal relations: primary, consequential, and compensatory. Albeit being an oversimplified classification, as Sass acknowledges, it allows for a more nuanced distinction between different kinds of causal relations.

Primary relations, according to Sass, describe a primary cause with a direct consequence, such as a neurological dysfunction that leads to a certain symptom or set of symptoms (Sass 2010, p. 648). The process by which the primary cause gives rise to its consequence is entirely operative. The individual has no awareness of or control over it; it takes place automatically, on a pre-reflective plane. While the neurocognitive disturbances underlying schizophrenia have proven difficult to establish, Nelson et al. (with Sass) (Nelson et al. 2014a; Nelson et al. 2014b) suggest that more fine-grained research can uncover respective correlates, e.g. research on efference copies. Efference copies are the neural signals that help to distinguish endogenous (self-generated) from exogenous (other-generated) stimuli by dampening stimuli that are generated by the individual themselves. Compare, e.g., being tickled by someone else to tickling yourself. In the latter case, the endogenous stimulus is dampened, leading to a dampened sensation of barely being tickled at all, while in the first case, the same stimulus generated by someone else might leave one doubled over with laughter. A failure in these neural signals leads to difficulties in distinguishing self-generated stimuli from other-generated stimuli and may thus, in turn, result in a diminished sense of self (Nelson et al. 2014a, pp. 14-15). Primary disturbances do not have to occur on the neurobiological level. Sass elaborates, e.g., on primary or operative hyperreflexivity (as opposed to a more reflective, secondary hyperreflexivity), denoting "a process afflicting the more fundamental levels of intentionality" (Sass 2010, p. 648). It is a passive and pre-reflective process in which experiences that the individual is normally unaware of push to the surface of awareness and become focal. It results in an altered way of experiencing one's selfhood, e.g. through the loss of a sense of automaticity of one's movement, resulting in a heightened awareness of the normally transparent field of experience.

Consequential relations describe processes that are not entirely passive as the ones just described, albeit not fully conscious or volitional, either (Sass 2010, p. 649). In the case of consequential hyperreflexivity, the heightened scrutiny of an irritable feeling might result in an exacerbation of this sensation (Sass and Parnas 2007, p. 83). For example, the delusional motor control typical of schizophrenia-spectrum disorders (i.e. the belief that one's movements are controlled by an external force) might be conceptualized as a consequence of the heightened scrutiny of the sensation of not being able to distinguish self- from other-generated stimuli (Nelson et al. 2014a). That is, an individual who cannot distinguish someone else's touch from their own might, as a consequence, come to experience their own touch as being controlled by an external 
force. The initial irritable sensation does not have to be a somatic one: Sass and Parnas also refer to "odd visual appearances" that increase in oddness the more the individual is drawn to scrutinizing them (Sass and Parnas 2007, p. 83). In both cases, the individual is involuntarily drawn to paying hypervigilant attention to an odd sensation, whether initially somatic or not, which consequently leads to an exacerbation of the disturbance.

Compensatory relations are explicitly goal-directed reactions that make the third category of Sass's diachronic relations. Their aim is to compensate for the primary factor that is their cause (Sass 2014, p. 370; Sass and Parnas 2007, p. 84). Also described as defensive, these teleological reactions are actively elicited by the individual and are volitional, as opposed to the consequential reactions described above. However, just as consequential reactions, compensatory reactions are often counterproductive. They threaten to result in more suffering rather than less and can become symptomatic of a disorder themselves. In response to a more basic disturbed sense of self, such as the above described inability to distinguish between self- and othergenerated stimuli and the resulting diminished self-presence, an individual might actively adopt a hyperreflexive stance, trying to re-establish the diminished sense of self. This, however, often results in an enhanced sense of unfamiliarity, thus perpetuating the disturbance rather than alleviating the distress (Sass 2010, p. 649).

We have seen that Sass identifies three types of causal relations: primary, consequential, and compensatory, differing by the degree of volition and goal-directedness of the individual. In the next section, I will investigate how they relate to the experiences of trauma.

\subsection{Relations of phenomenological causality in trauma}

In trauma research, the relationship between the experience of a potentially traumatizing event and subsequent mental health is mainly construed in terms of causality. The above presented taxonomy can thus be seen as a refinement of the generally assumed causal relation between a traumatizing event and adverse mental health outcomes. In what follows, I shall leave aside the relation between the event and post-traumatic experiences. Instead I will focus on the relations holding between the individual's experience of the event and their experience of subsequent distress. I am going to draw on Jessica Stern's memoir Denial (Stern 2010) to illustrate the discussion with a concrete case study. In her book, Stern recounts her experience of being raped at gunpoint as a girl and elaborates on the way in which the event impacted her throughout her life.

Primary relations in trauma The experience of a traumatizing event has been shown to elicit neurochemical imbalances and alterations in the brain (e.g. Bremner 2006; Tan 2013; van der Kolk 2015; Yehuda 2002). These can be identified to play a primary, operative role in the disorder. While the event itself may be understood as a primary cause for alterations in experience and can be described as 'having implications,' I shall focus here on the causal and implicatory relations between experiences of trauma. One can think, for example, of an individual being threatened with a cap gun. While they are not in any actual danger of being shot, they experience the assault as life threatening. Reading the words 'showed us gun, don't scream' she put down for a police report 
following the assault, Stern reports over 30 years later: "I feel a jarring in me, something quite hard and harsh forming in my veins, as if my blood were forming shards. This is a familiar feeling. I become a soldier if I am truly threatened" (cf. Stern 2010 , p. 17). The fact that the perpetrator revealed the gun to be a mock after the assault did not dampen the effect that being threatened with it had - and continues to have - on Stern. When a biological stress response is thus triggered by the experience of a potentially traumatizing event and cannot be contained by the organism, levels of norepinephrine and cortisol can be affected long after the perceived threat has passed. These alterations, in turn, affect the individual's experience after the traumatic event. Increased circulating levels of the neurotransmitter norepinephrine, which plays a central role in the regulation of stress responses, lead to increased alertness and hypervigilance and promote the encoding of emotional memories, such as those involving fear. Levels of cortisol, which helps contain the stress response by calming the sympathetic nervous system, are found to be low in individuals diagnosed with PTSD, and thus fail to counteract the heightened effects of the neurotransmitter. It is suggested that this neurochemical imbalance is a direct, primary cause not only for hypervigilance but also for the formation of enhanced traumatic memory, involving involuntary, intrusive memories and flashbacks (Elzinga and Bremner 2002; Sherin and Nemeroff 2011; Yehuda 2002), all of which are symptoms of PTSD listed in the DSM5 as "intrusion symptoms" (APA 2013, p. 271). The relation is a purely operative one that the individual plays no active role in.

Consequential relations in trauma The purely operative reactions described above can be distinguished from consequential reactions that are neither entirely operative nor fully conscious or volitional. When an intrusive memory or thought occurs, the individual might be drawn to paying hypervigilant attention to it. As a consequence of this kind of rumination, feelings associated with the event, e.g. guilt or shame, or somatic stress symptoms (e.g. raised heartrate) may arise and increase in intensity (van der Kolk 2015, p. 41). The person threatened with a cap gun might, e.g., be overcome by shame at not fighting back. As Jessica Stern reports: "here is what shames me to the core: I thought he was going to kill me, but I did not fight him" (Stern 2010). At the same time, the memory of the perceived threat can elicit a (somatic) re-experiencing of that fear, despite the knowledge that no actual threat was present, which might plausibly reinforce the experience of shame, as Stern's citations demonstrate. Due to the nature of the initial stimulus - the intrusive memory - the individual is drawn to ruminate on the thought or image and is pulled into it, thus exacerbating the emotional or somatic response the memory evokes. Further scrutiny of phenomena of this kind might help to explain the symptoms in the DSM's category D: "negative alterations in cognition and mood" (APA 2013, pp. 271-272).

Compensatory relations in trauma Compensatory reactions can also be referred to as coping mechanisms and are as such an inherent part of trauma discourse. Unable to make sense of the distressing event, an individual develops strategies to cope with the traumatic event they have been exposed to. As opposed to consequential reactions, this reaction is goal oriented in nature: the goal is to cope, that is, to find a way to go on after the horrifying experience. I argue that we can, in fact, identify two types of compensatory relations in trauma: those that are volitional (as covered in Sass's 
taxonomy), and those that are not. Individual experiences may fall in the gray area inbetween, where only some degree of volition is involved. What distinguishes them from consequential relations is their goal-directedness. Emotional numbing can serve as a prime example for standing in a compensatory relationship to the traumatizing event: The individual, confronted with a distressing experience, dissociates, denies, forgets, rather than having to bear the memory of the ghastly event. The memory of the trauma is suppressed. Taking the form of denial or partial amnesia, this defensive, teleological reaction is often aided by drugs or alcohol, and as such involves at least a certain degree of volition. Also "persistent avoidance", another one of the DSM's diagnostic criteria for PTSD, can be conceptualized as a compensatory reaction (APA 2013, p. 271). Examples of emotional numbing that involve some degree of volition of the affected individual can be found in the trauma literature, e.g., in Lidia Yuknavitch's The Chronology of Water, or Roxanne Gay's Hunger (Yuknavitch 2017; Gay 2017): in the first, Yuknavitch recounts how she (ab)used drugs and alcohol to help her cope with her traumatizing past; in the latter, Gay describes how she turned to food in an attempt to deal with her suffering. The potentially harmful side of these coping strategies is apparent: not only do alcohol, drugs, and eating disorders have a detrimental effect on the individual's physical health, they also threaten to have negative effects on their social and professional life. Stern, in contrast, did not have an active role in her numbing and forgetting. She reports:

"I feel a void. Something got cut out of me in that hour-my capacity for pain and fear were removed... my spirit had travelled... toward the infinite nothingness of indifference. A soft blanket of numbness descended like snow from the heavens, obscuring and protecting me from terror. Instead of fear, I felt numb. Instead of sadness, I experience a complete absence of hope" (Stern 2010, p. 25).

Stern did not recall the horror of being raped for many years after the event, mirroring the "[i]nability to remember an important aspect of the traumatic event(s) (typically due to dissociative amnesia and not to other factors such as head injury, alcohol, or drugs)" mentioned in the DSM-5 criteria (APA 2013, p. 271). Stern's experience of emotional numbing appears to be a case of a coping strategy but does not involve any volition or intention at all. Hence, it fits neither into Sass's category of a compensatory relation, nor can be it be described as consequential. The category of primary relations does not capture the experience, either: even if we were able to identify the neural and biological correlates of the experience, it would not sufficiently describe Stern's experience of the emotional numbing caused by her assault. Thus, I suggest for compensatory relations to allow for non-volitional goal-oriented reactions such as Stern's experience of denial. This demonstrates that the taxonomy is indeed oversimplified. It goes without saying that actual human experience is not as clear-cut as the categories presented.

Hence, we have seen that the causal relations identified by Sass can be applied to experiences of trauma. What all of Sass's causal relations have in common is that the cause may cease to exist while the effect continues to be present. This holds, too, for Stern's experience of emotional numbing. Other relations between experiences can, however, not be described in causal terms. This raises the issue of relations of 
phenomenological implication, which may hold between two experiences neither of which is caused by the other.

\section{Phenomenological implication}

\subsection{Louis Sass's phenomenological taxonomy of relations of implication}

Phenomenological implication encompasses relations between symptoms that occur simultaneously, according to Sass. He identifies equiprimordial, constitutive, and expressive relations that can hold between symptoms which stand in a non-causal relationship to one another but are not merely correlative, either. Thereby, he adds another dimension to our understanding of how symptoms relate to one another. This may be of relevance for treatment and intervention, as will become clear in the following. I will begin here with a description of the implicatory relations Sass identifies and how they might be applied to trauma, before elaborating in more detail on the possible diachronicity of relations of implication in the subsequent section, thus parting ways with Sass.

Equiprimordial relations hold between experiences neither of which is understood as more basic or fundamental than the other (Sass and Parnas 2007, p. 78). In other words, neither of the experiences can be identified as primary or secondary, in contrast to the relations described above. In this category, experiences are understood to be "two aspects of a single whole that we simply happen to describe from two different angles of vision" (Sass 2010, p. 644). Sass argues that hyperreflexivity and diminished selfpresence typical of schizophrenia can be understood as two "aspects of a fundamental (noetic) disturbance of the act of awareness" (Sass 2010, p. 644). That is, rather than thinking of the symptoms as causing one another, they can be conceptualized as complementary aspects of the same fundamental disturbance of ipseity. Each implies the other: the experience of one is part and parcel of the experience of the other. In categorizing the relation between symptoms as equiprimordial, the enquiry focuses on the relationship between the symptoms. The question of the cause of the symptoms is left aside.

Constitutive relations hold between acts of awareness and the specific content of experience. Here, Sass draws on Husserl's distinction between noetic and noematic aspects of experience. Noetic aspects are fundamental intentional processes underlying experience. In other words, they are the acts of awareness that form or give rise to specific experiences (Sass 2010, p. 639). Noematic aspects, then, are the perceptual content of this experience, whether in the presence of a physical object (e.g. the object that is seen or touched) or the absence thereof (e.g. the object that is remembered or hallucinated) (Husserl 1983, p. 223). ${ }^{5}$ Noesis and noema stand in a constitutive relationship to one another: "any consciousness is a consciousness of something," Husserl writes (Husserl 1983, p. 234). One cannot be without the other. Likewise, disturbances of the fundamental, noetic aspects of experience constitute disturbances in noematic perceptual content (Sass 2010, pp. 639, 645). When a fundamental intentional process is disturbed, so will the specific experiences that are constituted by it be: a

\footnotetext{
$\overline{5}$ See, e.g. Smith (2013) for a summary of Husserl's distinction between noesis and noema.
} 
fundamental disturbance of one's sense of self will constitute a disturbed experience of how one relates to the world, experienced as a loss of hold or grip that is often cited in the context of schizophrenia (Sass 2010, p. 645). Sass emphasizes that the constitutive relation is not a temporal one. He writes that "[constitution] should not be confused with a literal creation nor conceived as a temporal succession. There is not first the fact or process of subjectivity and only then the associated world" (Sass 2014, p. 369). It is not the case that first there is a disturbance in the structure of experience and then a disturbance of the specific experience follows. Instead, the specific experience could not occur independently of the act of awareness; it is enabled and, in this sense, constituted by it, and so is its disturbance. However, this relation can not only be described in synchronic terms, as I will demonstrate below.

Expressive relations describe "situations in which the (noematic) content of mental life seems to represent or express, in a more specific way, what appear to be more general formal or structural characteristics of mental life" (Sass 2010, p. 646, emphasis in original). Again, the schizophrenic individual's delusion of motor control, such as the feeling of one's movement being controlled by a computer inserted into one's brain, can serve as an example (Frith 2000, p. 358). The experience of not being in control of one's movements can be described in consequential terms as resulting from a more basic, neurocognitive malfunction; it can furthermore, regardless of the causal story neurology might tell, be understood from a phenomenological perspective as expressing a more general, noetic disturbance of the sense of self, i.e. of not being able to draw a clear distinction between self and other with regard to agency (Sass 2010, pp. 646647). That is, the experience of not being in control of one's movements cannot be understood independently of the disturbance of selfhood underlying it. While a cause may cease to exist without its effect doing so, this does not hold true for relations of implication: once the fundamental intentional process that constitutes a specific experience ceases to be disturbed, so will the disturbance which expresses it.

We have seen that equiprimordial, constitutive, and expressive relations may hold between experiences that are neither caused by one another, nor merely correlative. Their relation is one of implication, that is, the experiences cannot be thought of as separate phenomena: the absence of one would lead to the elimination of the other. According to Sass, the three categories which are identified as part of phenomenological implication allow to describe the non-temporal relations of experiences that are occurring simultaneously. However, by applying the three categories to experiences of trauma, I shall demonstrate that phenomenological implication does not have to be restricted to synchronous experiences.

\subsection{Relations of phenomenological implication in trauma}

Traumatic experiences, too, can be conceptualized in terms of implication. I suggest that phenomenologically inspired research promises to reveal relations between the experiences of traumatic events and subsequent distress that have, so far, remained underexplored. A discussion of relations of trauma in terms of causality leaves out an important and informative dimension of their experience: implication. In the following, it will become clear that the implication addressed is not necessarily one between simultaneously occurring experiences. Therefore, I will address the possibility of diachronic relations of implication, specifically 
between the experience of a traumatizing event and subsequent distress, in more detail in the subsequent section.

Equiprimordial relations On Sass's account of hyperreflexivity and diminished selfpresence as two aspects of a fundamental disturbance of the act of awareness, these equiprimordial symptoms cannot be thought of as separate from one another: the experience of one implies the experience of the other. Two symptoms that are phenomenologically distinct yet appear inseparably as two sides of one coin can be classified as equiprimordial. It is plausible to assume that relations of equiprimordiality can also be identified between experiences of trauma. We can think, for example, of a certain kind of change in temporal experience such as a sense of foreshortened future, which may be described as a loss in interpersonal trust amounting to a change in ones style of anticipation, as brought forth by Ratcliffe et al. (2014). There may well be similar changes in one's experience of time which do not involve a loss of interpersonal trust and vice versa. However, it is worth considering whether two such experiences might be equiprimordial, as identifying an equiprimordial relationship between two apparently distinct symptoms has the advantage that the treatment of one would also benefit the healing of the other.

Expressive relations Frequently co-occurring symptoms that share a common cause but could conceivably occur independently of one another do not fall under this category. For example, the "calm in the face of danger but fear in response to innocuous sounds or scents" (Stern 2010, p. Xv) that Stern reports do not seem to imply one another. The calm in the face of life threating situations she routinely experiences does not imply her aggravation at the sound of a ticking clock, nor the other way around. However, there still appears to be a certain kind of relationship between those two experiences that goes beyond accidental co-occurrence. What they have in common is that they are both expressive of a malfunctioning fear response. In other words, both the exhibiting of an unusual calm when faced with danger and the fearful reaction to hearing the clock's ticking imply a disturbed stress response. In these cases, treatment of the common, underlying disturbance would alleviate both symptoms, but treating one would not necessarily result in a relief of the other. To date, psychiatric research has, to my knowledge, not explored these different relations of post-traumatic experiences. Empirical research informed by phenomenological theory promises to confirm the assumption that various kinds of relations of implication-besides the causal relations often discussed - can be identified, and thereby further add to our understanding of trauma. Bringing attention to the difference between, e.g. equiprimordial, coexpressive, and correlative symptoms may shape therapeutic intervention that is better geared towards the disturbances at hand.

Constitutive relations As discussed above, a disturbance on a fundamental level of the structure of experience might imply a disturbance of the specific content of experience and thus be constitutive of it. This might best be illustrated by the use of an example: take the loss of trust often reported after trauma, e.g. by survivors of deliberate, interpersonal violence: 
\#1. I have kept myself distanced from others throughout most of my life until my mid 20s. Looking back I know now that it has been at least partly because of lack of trust in other's and generally feeling vulnerable and unsafe around people.

\# 21. In the past: I was very cautious and believed everyone would let me down. I was needy and will take things very personally and being oversensitive. Now: I am able to trust people, but I believe trust is earned so it still does take time for me to trust people. I don't immediately think everyone is bad but I think it is sensible to be cautious and then open up slowly once the person has showed me they are trustworthy and earned my trust.

\# 34. Always basic feeling of mistrust. ${ }^{6}$

The individuals are faced, not only with the specific loss of trust in another person- - the perpetrator(s) - but with a disruption of fundamental assumptions about others' trustworthiness in general and of their own "sense of safety in the world" (Herman 1992, p. 51). This structural change in experience (noesis) in the aftermath of the traumatizing event amounts to an untrusting attitude, which can be described as constituting another person as untrustworthy (noema).

As social beings, we depend on a sense of safety in the world, a sense that others are generally well-meaning and trustworthy. This is essential for social functioning, as one is unable to form relationships without it (Herman 1992). We trust not only our closest family and friends but the people we encounter in our day-to-day lives: colleagues, people in the library, on the train, in the café are encountered as trustworthy. These experiences of trust are pre-reflective, underlying, and pervasive; not directed at each of the individuals one encounters but directed at others in general. As such, the underlying sense of trust is constitutive of more concrete, explicit experiences of trust. It becomes salient when it needs to be reconsidered in situations that are experienced as potentially dangerous: is the armed soldier on the train worthy of my trust? Is the person shouting insults? In these cases, I might come to experience the other as not trustworthy. However, this experience of a failure of trust is a "departure from our default attitude" (Ratcliffe 2017, p. 123; my emphasis), while the default attitude remains intact.

In contrast, the above testimonies show that the ability to trust others in general is impacted: the default attitude of the traumatized individual is altered, or, in the case of traumatizing experiencing in early childhood, never developed to incorporate the possibility to trust others in the first place. The experience of another individual deliberately inflicting pain on us goes against the very fundamental sense of being in a safe world. Extreme cases thereby destroy not only the victim's trust in the perpetrator but shatter a general assumption about the trustworthiness of others. The experience of a violent breach of trust can present an immediate re-configuring of fundamental structures of experience. Some events of deliberate interpersonal violence are experienced as a violent breach of this basic sense of trust, rather than merely a loss of trust in the perpetrator. An experience that erodes the individual's capacity for trust in this way can therefore be described as causing (in a primary sense) the individual's fundamental sense of trust to erode, which in turn implies an inability to trust others in the aftermath of the event.

\footnotetext{
${ }^{6}$ The testimonies were collected in an online survey I conducted in 2020, which received ethical approval by the University of York Arts and Humanities Ethics Committee***.
} 
This disturbance, I shall argue in the following, has a temporal structure. It may be expressed-sometimes years and decades after the event - in individual instances of failing to trust a specific person when, formerly, this trust would have been easily and unthinkingly granted. Moreover, the experience of not being able to trust someone can itself be described in temporal terms, as I will demonstrate in the following. A discussion of phenomenological implication cannot be restricted to terms of synchronicity. The temporality of relations of implication needs to be taken into account, too.

\section{Diachronic relations of implication}

At this point, we need to digress from Sass's framework and his proposed association of causality with diachronicity, and implication with synchronicity of symptom occurrence. I will focus here on the potential significance of the diachronicity of relations of implication between experiences of trauma. Sass and Parnas briefly acknowledge the distinction between synchronic and diachronic processes to be a merely "pedagogical" one, as "all conscious processes are in fact intrinsically temporal in nature" (Sass and Parnas 2007, pp. 76, endnote 16). The simplification has the advantage of allowing for a more straightforward classification of relations. The merit of phenomenological implication, on this view, is that it allows us to describe the relations between simultaneously occurring symptoms that causation cannot capture. However, it is not restricted to the description of these. By conflating phenomenological implication with the description of synchronic relations, Sass neglects the fact that phenomenological implication may in fact be very fruitfully applied to the description of successively occurring experiences.

In regard to the study of post-traumatic experiences, taking the intrinsic temporality of experience into account is particularly informative. The 'post' in 'post-traumatic' marks rather obviously the diachronicity of trauma, from the experience of a traumatizing event to the subsequent alteration of experience. I argue that, while an alteration in perception or behavior post trauma might temporally succeed the event, it can, at the same time, be implied in the experience of the event. We are explicitly faced with a case of phenomenological implication with a temporal structure. This is only possible to account for if one allows for phenomenological implication to describe both synchronically and diachronically occurring experiences. I mentioned above that a traumatizing experience may erode an individual's pervasive sense of trust which constitutes their inability to enter into trusting relationships with specific people in the aftermath of the event. There are two ways in which this implication can be described as having a temporal structure: on the one hand, the erosion of trust may be phenomenologically present as an altered anticipatory style, which is an intrinsically temporal experience by virtue of its being an apperception in Husserl's sense. On the other hand, it can be experienced as unfolding over time.

\subsection{Intrinsic temporality}

In order to clarify the notion of anticipatory style and thereby offer one way of accounting for the temporality of relations of implication, I will begin with a brief elaboration of Husserl's account of time consciousness. Husserl argues that every experience is intrinsically temporal. One perceives not only time slices of now- 
moments: conscious experience is in constant flux. This counts too for experiences of implication. Therefore, phenomenology ought not only to describe experiences in terms of their constitutive givenness, but also in terms of their temporality. Husserl calls these two lines of enquiry static and genetic phenomenology respectively and advocates, in his later work, for their interconnectedness (Husserl 1966, p. 336 ff., Husserl 1973, p. 34 ff.; cf. Steinbock 1998).

While a full elaboration of Husserl's account would exceed the scope of this paper, an example should serve to illustrate its applicability to experiences of trauma. Some implications of an experience, such as the breach of trust that an event of deliberate interpersonal violence presents, are immediate and as such phenomenologically present in the experience. Alice Sebold's report illustrates this poignantly: "When I was raped I lost my virginity and almost lost my life. I also discarded certain assumptions I had held about how the world worked and about how safe I was" (quoted in: Herman 1992, p. 51). The individual's sense of being in a world shared with people that are generally trustworthy may erode at the time of the traumatizing experience. This alteration of one's fundamental structure of consciousness can be described as constituting one's experience of trusting others in the aftermath of the event as impossible. It is a relation of implication, not causation, as explicated above.

Moreover, this implication can be described as diachronic because the alteration amounts to a loss of the possibility of a certain kind of future. We can account for the temporality of this experience by appealing to the phenomenological concept of apperception. An apperception is, according to Husserl, the perception of something that is not directly given in present experience, like the backside of a tree trunk or the notes of a melody other than the one I currently hear. It is, in other words, the perception of possibilities, or more specifically the perception of horizons belonging to an intentional object which are possible to perceive (e.g. Husserl 1983). Seeing a tree trunk, I perceive not only the bark that is in my field of vision; I have an apperception of it having a backside and the sense that, if I were to walk around the tree, different parts of its trunk would come into view. I anticipate its location, shape and colors, and - on walking around the tree-my anticipations are fulfilled while dynamically giving rise to new apperceptions. ${ }^{7}$ Any perception has this intrinsically temporal anticipation-fulfilment structure (Ratcliffe 2017). Husserl explicates further that an experience includes not only the current impression of what is directly given, but also what he calls retentions of what has just passed and protentions of the horizons one anticipates to varying degrees of likelihood, i.e. that are possible, likely, unlikely, etc. to be perceived in the future (e.g. Husserl 1962, p. 200 ff.). Listening to a melody, I do not only perceive the current note. My perception of the note is marked by the retentions of the notes that have preceded it, and the protentions of the notes that are yet to follow. The presence of these retentions and protentions allows me to perceive the present note as part of a melody with a temporal structure instead of as an individual, isolated nowmoment. Importantly, Husserl stresses that these apperceptions are integral to one's present experience. In other words, one cannot have a present experience without the apperception of the experienced object's horizons: I cannot hear the note independent of its occurrence in the melody.

\footnotetext{
${ }^{7}$ It is worth noting that apperceptions are not restricted to one mode of perceiving: I can, e.g., visually perceive the rough, brittle toughness of the bark were I to reach out and touch it.
} 
Ratcliffe, drawing on Husserl, emphasizes that not only perceptions of tree trunks and melodies have this intrinsically temporal anticipation-fulfilment structure or anticipatory style: "in order to encounter things — regardless of what they might be - in one or another way, experience must have a global form, a temporal structure whereby coherently organized possibilities are actualized in line with confident anticipation "(Ratcliffe 2017, p. 130; emphasis in original). In fact, he draws on post-traumatic erosion of trust to demonstrate that this temporal structure holds of relations of implication, too. When one's sense of being in a world shared with people that are generally trustworthy erodes, so does the anticipation-fulfilment structure of one's experience. Where one formerly met others with the habitual confidence of an undisturbed basic trust, the erosion of this basic trust implies one's inability to trust another person in particular. We can see now that this takes the form of an altered anticipatory style: one's apperceptions contain different possibilities than they formerly did. The possibility for trusting the other is no longer part of the encounter's horizonal structure; it has been replaced by the anticipation of threat (Ratcliffe 2017). Not meeting the person in the café, the library, or on the train with trust is no longer a departure from one's default attitude but is implied by one's altered default attitude, as the above testimonies illustrated.

\subsection{The unfolding of trauma}

I want to add to this that the experience of an implication may unfold over time. The pervasive loss of trust in others, not only the perpetrator, is an experience that only gradually becomes salient after the event. It might take months or years for the survivor to become aware of the impact that the traumatizing event had on their most fundamental structures of experience - if a full reckoning ever comes about. Here, too, we are faced with the diachronicity of the experience of a loss of trust that a traumatizing experience might imply. At the first instance of mistrust, e.g. the experience of not being able to trust the perpetrator to mean you well, there is no phenomenological difference between not being able to trust this specific individual and not being able to trust anyone in general. Only when instances accumulate does the full, fundamental disturbance come to the fore. This claim is supported by reports of survivors retrospectively becoming aware of features of the respective traumatizing experience. On thinking back to her abuser asking whether she and her sister were still clothed, Stern notes: "Would we still be clothed? We were wearing leotards. But I know the answer to that question now: I would never be clothed again" (Stern 2010, p. 18). At the time of the assault, she was presumably painfully aware of her feeling of nakedness, helplessness, and vulnerability. Only time showed that this feeling was not going to go away by getting dressed again once the rapist left. The traumatic experience implied a sense of pervasive vulnerability that unfolded over time, becoming apparent in Stern's difficulty urinating shortly after the rape: "I began to walk with crotch held back to prevent intruders, muscles so tight I have to will myself to urinate, sometimes even now" (Stern 2010 , p. 21). Note, also, the author's use of the present tense in this unusually ungrammatical sentence in her otherwise strikingly eloquent memoir. It seems that not only did the traumatizing experience imply a future kind of experiencing; the past may also be experientially present in the now-experience.

The development of trauma is not straightforward, and amnesia is not the only factor obscuring the linearity of trauma narratives. The trauma's lasting impact unfolds, often 
for months and years after the event. As I have shown, this does not mean that the relationship between the experience of a traumatizing event and subsequent distress cannot be described in terms of implication. Allowing for diachronicity of relations of implication might enable a better understanding of the experience of trauma over time. Hence, I have illustrated the possible diachronicity of relations of implication in traumatic experience. Implication can be described in at least two ways as having a temporal structure: drawing on Husserl's phenomenology of time consciousness, I have demonstrated that trauma may involve an altered anticipatory style. Moreover, we have seen that trauma can be experienced as unfolding over time. Further phenomenologically inspired research thus promises to contribute to a better understanding of experiences of trauma.

\section{Concluding remarks}

The relationship between the experience of a traumatizing event and post-traumatic alterations in experience are manifold in kind and can be scrutinized in various ways. Both phenomenological causality and implication can be usefully applied to a diachronic relationship like this. I have drawn here on Louis Sass's phenomenological taxonomy, in which he presents six different ways in which to conceive of relationships between experiences: three of causation and three of implication. I have thus demonstrated that his framework, developed for the study of symptoms of schizophrenia, can also be applied to the relationships of traumatic experiences. In order to make sense of the relationship between the experience of a traumatizing event and subsequent distress, which is one that unfolds over time, I expanded Sass's taxonomy to demonstrate that phenomenological implication can also be applied to diachronic relations. Experiences of trauma, like all other experiences, are intrinsically temporal. Moreover, their often severe implications unfold over time. Further phenomenological research can expand this account, adding to a more detailed understanding of the experience of trauma, both at the time of calamity and in its aftermath, as well as relations between the various experiences the trauma survivor is faced with. Hopefully, an in-depth description of traumatic experiences can offer better ways of explaining them. A thorough understanding of the way in which traumatic events leave their traces on the individual's experiential life promises to inform trauma intervention, e.g. by taking into account relations between the various symptoms of PTSD. It might, furthermore, help to inform strategies to foster resilience in groups vulnerable to traumatization, such a soldiers and first responders, by mapping how a traumatizing experience relates to the development of lasting distress. I suggest that an account that brings into focus the constitutive relation between fundamental acts of awareness and their disruption through trauma could be particularly informative, shedding light on why specific events are experienced as traumatic, and why some individuals develop lasting mental health issues, while others do not. Hence, the phenomenological study of trauma may contribute to a better understanding of experiential causation and implication, our experience of temporality, the self in relation to others, and more, and furthermore promises to have practical implications for the treatment of post-traumatic distress. ${ }^{8}$

\footnotetext{
${ }^{8}$ Word count excl. Footnotes and bibliography: 7610.
} 
Acknowledgments I would like to thank Matthew Ratcliffe for his thorough feedback on my work, and (in alphabetical order) Christina van der Feltz-Cornelis, Joel Krueger, Jennifer Radden, Danilo Reuben, and especially Louis Sass for illuminating conversations on the topic and their comments on earlier drafts of this paper, as well as the two anonymous reviewers for their valuable comments on the latest draft. My sincerest thanks to the participants of the study for their insightful contributions.

Funding No funding was received to assist with the preparation of this manuscript.

\section{Compliance with ethical standards}

Conflict of interest The author declares that they have no conflict of interest.

Open Access This article is licensed under a Creative Commons Attribution 4.0 International License, which permits use, sharing, adaptation, distribution and reproduction in any medium or format, as long as you give appropriate credit to the original author(s) and the source, provide a link to the Creative Commons licence, and indicate if changes were made. The images or other third party material in this article are included in the article's Creative Commons licence, unless indicated otherwise in a credit line to the material. If material is not included in the article's Creative Commons licence and your intended use is not permitted by statutory regulation or exceeds the permitted use, you will need to obtain permission directly from the copyright holder. To view a copy of this licence, visit http://creativecommons.org/licenses/by/4.0/.

\section{References}

APA. (2013). Diagnostic and Statistical Manual of Mental Disorders (Fifth Edition). https://doi.org/10.1176/ appi.books.9780890425596

Ataria, Y. (2018). Body Disownership in complex posttraumatic stress disorder. New York: Palgrave Macmillan. https://doi.org/10.1057/978-1-349-95366-0.

Bendall, S., Jackson, H. J., Hulbert, C. A., \& McGorry, P. D. (2008). Childhood trauma and psychotic disorders: A systematic, critical review of the evidence. Schizophrenia Bulletin, 34(3), 568-579. https:// doi.org/10.1093/schbul/sbm121.

Borsboom, D., \& Cramer, A. O. J. (2013). Network analysis: An integrative approach to the structure of psychopathology. Annual Review of Clinical Psychology, 9, 91-121. https://doi.org/10.1146/annurevclinpsy-050212-185608.

Bremner, J. D. (2006). Traumatic stress: Effects on the brain. Dialogues in Clinical Neurosciences, 8(4), 445461.

Elzinga, B. M., \& Bremner, J. D. (2002). Are the neural substrates of memory the final common pathway in posttraumatic stress disorder (PTSD)? Journal of Affective Disorders, 70(1), 1-17.

Frith, C. (2000). Explaining the symptoms of schizophrenia: Abnormalities in the awareness of action. Brain Research Reviews, 31(2-3), 357-363. https://doi.org/10.1016/S0165-0173(99)00052-1.

Fuchs, T. (2013). Depression, Intercorporeality, and Interaffectivity. Journal of Consciousness Studies, 20(78), 219-238.

Fuchs, T., \& Röhricht, F. (2017). Schizophrenia and intersubjectivity. An embodied and enactive approach to psychopathology and psychotherapy. Philosophy, Psychiatry, \& Psychology, 24(2), 127-142. https://doi. org/10.1353/ppp.2017.0018.

Gay, R. (2017). Hunger. New York: Harper Collins.

Herman, J. (1992). Trauma and recovery. New York: Basic Books.

Husserl, E. (1962). Phänomenologische Psychologie, Vorlesungen Sommersemester 1925. Den Haag: Nijhoff.

Husserl, E. (1966). Analysen zur passiven Synthesis (M. Fleischer, Ed.). Den Haag: Nijhoff.

Husserl, E. (1973). Zur Phänomenologie der Intersubjektivität (I. Kern, Ed.). Den Haag: Nijhoff.

Husserl, E. (1983). Ideas pertaining to a pure phenomenology and to a phenomenological philosophy I (F. Kersten, Trans.). Dordrecht: Kluwer.

Jaspers, K. (1963). General psychopathology. Manchester: Manchester University Press. 
McNally, R. J., Robinaugh, D. J., Wu, G. W. Y., Wang, L., Deserno, M. K., \& Borsboom, D. (2015). Mental disorders as causal systems: A network approach to posttraumatic stress disorder. Clinical Psychological Science, 3(6), 836-849. https://doi.org/10.1177/2167702614553230.

National Institute for Health and Care Excellence. (2018). Post-traumatic stress disorder [NICE guideline 1167. Available at https://www.nice.org.uk/guidance/ng116.

Nelson, B., Whitford, T. J., Lavoie, S., \& Sass, L. A. (2014a). What are the neurocognitive correlates of basic self-disturbance in schizophrenia?: Integrating phenomenology and neurocognition. Part 1. Schizophrenia Research, 152(1), 12-19. https://doi.org/10.1016/j.schres.2013.06.022.

Nelson, B., Whitford, T. J., Lavoie, S., \& Sass, L. A. (2014b). What are the neurocognitive correlates of basic self-disturbance in schizophrenia?: Integrating phenomenology and neurocognition: Part 2. Schizophrenia Research, 152(1), 20-27. https://doi.org/10.1016/j.schres.2013.06.033.

Nordgaard, J., \& Henriksen, M. G. (2018). Phenomenological psychopathology and quantitative research. In The Oxford Handbook of Phenomenological Psychopathology. London: Routledge, 941-951.

Parnas, J., \& Gram Henriksen, M. (2016). Mysticism and schizophrenia: A phenomenological exploration of the structure of consciousness in the schizophrenia spectrum disorders. Consciousness and Cognition, 43, 75-88.

Ratcliffe, M. (2017). Real hallucinations. Cambridge: MIT Press.

Ratcliffe, M. (2018). The phenomenological clarification of grief and its relevance for psychiatry. In The Oxford Handbook of Phenomenological Psychopathology. London: Routledge, 538-551.

Ratcliffe, M. (2020). Existential Feelings. In T. Szanto \& H. Landweer (Eds.), The Routledge handbook of phenomenology of emotions (pp. 250-261). London: Routledge.

Ratcliffe, M., Ruddell, M., \& Smith, B. (2014). What is a "sense of foreshortened future?" a phenomenological study of trauma, trust, and time. Frontiers in Psychology, 5, 1-11. https://doi.org/10.3389/fpsyg. 2014.01026.

Read, J., Perry, B. D., Moskowitz, A., \& Connolly, J. (2001). The contribution of early traumatic events to schizophrenia in some patients: A traumagenetic neurodevelopmental model. Psychiatry, 64(4), 319-345. https://doi.org/10.1521/psyc.64.4.319.18602.

Sass, L. (2010). Phenomenology as description and as explanation: The case of schizophrenia. Handbook of Phenomenology and Cognitive Science, 635-654.

Sass, L. (2014). Explanation and description in phenomenological psychopathology. Journal of Psychopathology, 20, 366-376.

Sass, L., \& Parnas, J. (2007). Explaining schizophrenia: The relevance of phenomenology. International Perspectives in Philosophy and Psychiatry. Reconceiving Schizophrenia. New York: Oxford University Press, 63-95.

Sass, L., Pienkos, E., \& Fuchs, T. (2017). Other worlds: Introduction to the special issue on the EAWE: Examination of anomalous world experience. Psychopathology, 50(1), 5-9. https://doi.org/10.1159/ 000456215.

Sass, L. A., Pienkos, E., Nelson, B., \& Medford, N. (2013). Anomalous self-experience in depersonalization and schizophrenia: A comparative investigation. Consciousness and Cognition, 22(2), 430-441. https:// doi.org/10.1016/j.concog.2013.01.009.

Schmidt, P. (2018). The relevance of explanatory first-person approaches (EFPA) for understanding psychopathological phenomena. The role of phenomenology. Frontiers in Psychology, 9, 1-16. https://doi.org/ 10.3389/fpsyg.2018.00694.

Sherin, J. E., \& Nemeroff, C. B. (2011). Post-traumatic stress disorder: The neurobiological impact of psychological trauma. Dialogues in Clinical Neuroscience, 13(3), 263-278.

Smith, D. W. (2013). Phenomenology. The Stanford Encyclopedia of Philosophy.

Steinbock, A. J. (1998). Husserl's static and genetic phenomenology: Translator's introduction to two essays. Continental Philosophy Review, 31, 127-134.

Stern, J. (2010). Denial. A memoir of terror. New York: Harper Collins.

Tan, L. (2013). Brain structure in post-traumatic stress disorder: A voxel-based mophometry analysis. Neural Regeneration Research, 8, 26.

van der Kolk, B. (2015). The body keeps the score. Penguin.

Yehuda, R. (2002). Post-traumatic stress disorder. The New England Journal of Medicine, 346(2), $108-114$.

Yuknavitch, L. (2017). The chronology of water. Portland: Hawethorne Books \& Literary Arts.

Publisher's note Springer Nature remains neutral with regard to jurisdictional claims in published maps and institutional affiliations. 